\title{
Neuropathic-like pain in psoriatic arthritis: evidence of abnormal pain processing
}

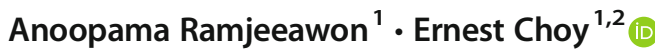

Received: 25 February 2019 / Revised: 12 June 2019 / Accepted: 20 June 2019 / Published online: 19 July 2019

(C) The Author(s) 2019

\begin{abstract}
Objectives The primary objective was to investigate the prevalence of neuropathic-like pain in patients with psoriatic arthritis (PsA). Secondary outcomes were to investigate whether mood, fatigue, pain, disease severity and fibromyalgia are associated with neuropathic-like pain in PsA patients.

Methods PsA patients were assessed for fatigue, mood, pain, disease activity and fibromyalgia using questionnaires. Neuropathic-like pain was assessed by PainDetect.

Results Sixty-four patients with PsA were recruited from the Rheumatology Outpatient Department. Of the 64 patients recruited, $26.6 \%$ had 'likely neuropathic pain' and $21.9 \%$ had 'possible neuropathic-like pain' according to the PainDetect questionnaire. Patients with 'likely neuropathic pain' had higher disease activity, health assessment questionnaire, patient global self-assessment score, tender and swollen joint counts, dactylitis, enthesitis, pain severity and interference with day-to-day activities, fatigue severity and impact, fibromyalgia, anxiety and depression than 'unlikely neuropathic pain' patients $(p<0.05)$. PainDetect score correlated with measures of disease activity, fatigue, depression, anxiety, Widespread Pain Index and Symptom Severity Scale (all $p<0.05)$. Most patients $(71 \%)$ with neuropathic-like pain fulfilled American College of Rheumatology 2010 fibromyalgia criteria. Patients with 'possible neuropathic-like pain' had scores between patients with 'likely neuropathic pain' and 'unlikely neuropathic pain'.

Conclusion Neuropathic-like pain as evidence of abnormal pain processing is common in patients with PsA. It is associated with higher disease activity and fibromyalgia. A significant proportion of patients had 'possible neuropathic-like' pain with intermediate disease and symptom score suggesting neuropathic-like pain as evidence of abnormal pain processing is a continuum rather than concurrent fibromyalgia.
\end{abstract}

Key Points

- Neuropathic pain is prevalent in psoriatic arthritis.

- Higher levels of pain, disease activity, fatigue, depression, anxiety and comorbidities in Psoriatic arthritis.

- Increased pain severity is associated with increased disease activity, fatigue, depression and anxiety.

Keywords Anxiety $\cdot$ Depression $\cdot$ Disease activity $\cdot$ Fatigue $\cdot$ Inflammatory arthritis $\cdot$ Neuropathic pain $\cdot$ Pain $\cdot$ PainDetect $\cdot$ Pain severity $\cdot$ Psoriatic arthritis

Ernest Choy

ChoyEH@Cardiff.ac.uk

School of Medicine, Cardiff University, Cardiff, UK

2 CREATE Centre, Section of Rheumatology, Division of Infection and Immunity, Cardiff University, Tenovus Building, Heath Park Campus, Cardiff CF14 4XN, UK

\section{Introduction}

Pain is the most common complaint in patients with musculoskeletal diseases. Patients with inflammatory arthritis (IA) such as rheumatoid arthritis (RA) ranked pain as the most important symptom [1], which has a major detrimental impact on their quality of life [2]. Despite advances in treatment for RA, many patients still suffer from pain [3].

Pain can be categorised into inflammatory, nociceptive and neuropathic [4]. Inflammation leads to the release of prostaglandin E2 and prostaglandin I2 which can sensitise 
nociceptors on sensory neurones to induce pain. In contrast, neuropathic pain is a type of pathological pain [5] and defined as "pain initiated or caused by a primary lesion or dysfunction in the nervous system" [6]. It can affect both the peripheral and central nervous system and may be caused by a variety of pathophysiological mechanisms such as inflammatory reactions and neuroplastic changes [7]. It is characterised by sensory abnormalities ranging from numbness to hypersensitivity (hyperalgesia/allodynia) [8], which can be objectively assessed by quantitative sensory testing (QST) which is a non-invasive method to quantify sensory nerve function, by quantifying the stimulus needed to elicit the perception of specific types of sensation. QST allows for quantification of assessment of perception thresholds for light touch, vibration, thermal and pain sensation [9].

Abnormal pain processing in the central nervous system, central sensitization, has been demonstrated consistently in neuropathic pain [10]. Central sensitization occurs when nociceptive stimulation results in increased excitability of neurons in pain pathways, resulting in pain hypersensitivity, including allodynia and hyperalgesia [5]. Central sensitization has also been demonstrated in rheumatic diseases such as RA $[11,12]$. In a previous study investigating the prevalence of neuropathic pain in RA, the most commonly identified neuropathic pain features were 'pain attacks like electric shocks' and 'pain with slight pressure' [11].

Patients with neuropathic pain typically experience pain that becomes chronic and less responsive to analgesic medication, as well as sleep disturbance, anxiety, depression and reduced quality of life compared with patients with chronic, non-neuropathic pain [13]. In addition to the negative effects in the individual with neuropathic pain, there are also negative effects on society - increased healthcare costs (increased medication needs, increased visits to healthcare providers) and loss of ability to work [14]. Neuropathic pain is in general underdiagnosed and undertreated. Even when diagnosed, it can often be mismanaged - these patients are frequently prescribed conventional analgesics such as non-steroidal anti-inflammatories which have limited efficacy in managing neuropathic pain [15], similarly opiates may not optimally manage neuropathic pain due to resistance or insensitivity [5]. Neuropathic pain is typically treated with antidepressants and anticonvulsants but may also benefit from psychological and occupational therapies to help the patient cope with the pain [5], as even when managed with appropriate pharmacology, benefits may be limited $[5,15]$. Understanding the cause, mechanism and symptoms experienced is key to selecting, and future development, of appropriate management of neuropathic pain [5].

The definition of neuropathic pain does not distinguish it from pain arising from neuroplastic changes associated with central sensitization so will be referred to as neuropathic-like pain. Of the inflammatory arthritides, studies to date of neuropathic-like pain have focused on RA; however, psoriatic arthritis (PsA) is another common form of inflammatory arthritis, but neuropathic-like pain and central sensitization have not been assessed in these patients and may impact on disease assessment similarly to RA. The aim of this study is to determine the prevalence of neuropathic-like pain and central sensitization using pressure pain threshold and mechanonociception testing [16] - and PainDetect questionnaire [17] in patients with PsA. The impact of neuropathic-like pain and central sensitization on comorbidities (depression, anxiety) and disease activity assessment will also be assessed.

\section{Methods}

During an eight-week period in 2017, all patients with PsA being treated at the Rheumatology department based at the Cardiff and the Vale University Health Board Trust were invited to take part in the study, either by post or in person by the study faculty when attending routine appointments at rheumatology clinics. Patients were eligible to be included in the study if they had a clinical diagnosis of PsA, were aged eighteen or over and consented to being included in this study. Patients were only excluded if they had phantom limb syndrome or complex regional pain syndrome or did not consent to taking part in the study.

The patients who were enrolled in this study completed a consent form, demographics form (component questions detailed under demographics section of Table 1) and a series of validated questionnaires (Table 1) [18-26], following which they underwent pressure pain threshold and mechanonociception testing and physical examination for enthesitis and dactylitis, on the day of presenting to the unit. The questionnaires were chosen to assess comorbidities and outcome measures that are known to affect pain experience. No follow-up was performed.

The PainDetect questionnaire results classified the patients as 'unlikely neuropathic', 'possible neuropathic' or 'neuropathic' groups. Secondary outcome measures included disease activity assessment, brief pain inventory score, tender and swollen joint count, examination for dactylitis and enthesitis, American College of Rheumatology (ACR) 2010 fibromyalgia (FM) questionnaire score, hospital anxiety and depression scale, fatigue severity score and fatigue impact scale.

Objective assessment of pressure pain threshold and mechanonociception was conducted using an electronic algometer (Somedic Algometer, Somedic SenseLab AB, Sösdala, Sweden) [27] and von Frey filaments (North Coast Medical Inc., Morgan Hill, California) [28].

von Frey filament testing was carried out on the mid-point between the wrist and elbow on the anterior surface of the forearms and on the skin over the medial end of the spine of each scapula to elicit the mechanical nociceptive threshold 
Table 1 Assessments and questionnaires conducted on each participant in the study

\begin{tabular}{|c|c|c|}
\hline Assessment & Outcome assessed & $\begin{array}{l}\text { Primary or secondary } \\
\text { outcome }\end{array}$ \\
\hline Consent form & Consent & $\mathrm{n} / \mathrm{a}$ \\
\hline Demographics form & $\begin{array}{l}\text { Demographics (age, sex, disease duration, } \\
\text { number of concomitant diseases, number } \\
\text { of medications) }\end{array}$ & $\mathrm{n} / \mathrm{a}$ \\
\hline $\begin{array}{l}\text { American College of Rheumatology } \\
2010 \text { fibromyalgia criteria }[18,19]\end{array}$ & $\begin{array}{l}\text { Widespread Pain Index, Symptom Severity } \\
\text { Score, fibromyalgia, Polysymptomatic } \\
\text { Distress Scale score }\end{array}$ & Secondary \\
\hline Brief Pain Inventory [20] & Pain severity, pain interference & Secondary \\
\hline Fatigue Impact Scale [21] & Fatigue impact & Secondary \\
\hline Fatigue Severity Scale [22] & Fatigue severity & Secondary \\
\hline Hospital Anxiety Depression Scale [23] & Anxiety, depression & Secondary \\
\hline Health Assessment Questionnaire [24] & Disability Index & Secondary \\
\hline Pain Detect Questionnaire [25] & Pain type & Primary \\
\hline $\begin{array}{l}\text { Patient Disease Activity } \\
\text { Assessment Questionnaire [26] }\end{array}$ & $\begin{array}{l}\text { PDAS score, tender joint count, } \\
\text { swollen joint count }\end{array}$ & Secondary \\
\hline Physical examination & Enthesitis, dactylitis & Secondary \\
\hline Electronic algometer testing [27] & Pressure pain threshold & Secondary \\
\hline von Frey filament testing [28] & Mechanical nociceptive threshold & Secondary \\
\hline
\end{tabular}

and the mechanical pressure sensation threshold. Electronic algometer testing was carried out at the mid-point of the anterior surface of the thigh and the medial end of the spine of scapulae, to elicit the pressure pain threshold (PPT). For electronic algometer testing and von Frey Filament testing, an average of three measurements taken were recorded-since multiple measurements are needed to reliably estimate the threshold being assessed [16], but considering the time taken for the full assessment for each patient for this study, it was decided to be acceptable to complete three measurements for pragmatic reasons.

The data was analysed using IBM SPSS Statistics for Windows, V23.0. Armonk, NY: IBM Corp. The data was tested for normality using Shapiro-Wilk. The results for all groups at baseline were analysed using ANOVA and posthoc analysis using Dunnett's test and then using independent samples $t$ test or independent samples Mann-Whitney $U$ test as appropriate, to analyse for significant differences. Pearson coefficient correlation testing was carried out to analyse how the parameters assessed varied with 'pain severity' and 'the PainDetect score'.

The study was approved by the South East Coast Brighton and Sussex Research Ethics Committee (17/LO/ 0147).

\section{Results}

Sixty-four patients with a clinical diagnosis of PsA, aged $\geq$ 18 years old, were recruited; their demographics are described in Table 2. From their PainDetect score, seventeen (26.6\%) patients were classified into the 'likely neuropathic pain' (NP) group, fourteen $(21.9 \%)$ patients were classified into the 'possible neuropathic pain' (PNP) group and $33(51.6 \%)$ patients were classified into the 'unlikely neuropathic pain' (UNP) group. In the NP and PNP groups, the majority of patients were female, compared with UNP group, where the majority of patients were male. Disease duration was longest and the number of concomitant diseases was highest in the NP and PNP groups compared with the UNP group, although these differences were not significant ( $p=0.161$ and 0.077). On average, the NP group was taking significantly more medications than the PNP and UNP groups $(p=0.025)$. There were 58 different comorbidities found in the patients enrolled, 15 seen in more than one patient, of which the most common were hypertension (31.0\%), type 2 diabetes (13.8\%), psoriasis (13.8\%) and depression (10.3\%).

Disease activity as measured by tender and swollen joint counts, pain score, patient global assessment, dactylitis and enthesitis scores were statistically significantly higher in the NP than that in the UNP group (Table 2). There were also statistically significant differences in these disease activity assessments in PNP versus UNP except for enthesitis and dactylitis, although for the latter the difference only just failed to reach statistical significance $(p=0.057)$. Across the three groups, disease activity was trending higher over the 3 categories, from unlikely neuropathic pain, to possible neuropathic pain, to likely neuropathic pain [29].

Similarly to disease activity, patients with NP and PNP were statistically significantly more likely have greater pain 
Table 2 Demographics and differences in disease activity, symptoms and comorbidities

\begin{tabular}{|c|c|c|c|c|}
\hline & $\begin{array}{l}\text { Unlikely } \\
\text { neuropathic pain }\end{array}$ & $\begin{array}{l}\text { Possible } \\
\text { neuropathic pain }\end{array}$ & $\begin{array}{l}\text { Likely } \\
\text { neuropathic } \\
\text { pain }\end{array}$ & $p$ value \\
\hline \multicolumn{5}{|l|}{ Demographics } \\
\hline Number (\%) & $33(51.6 \%)$ & $14(21.9 \%)$ & $17(26.6 \%)$ & NS \\
\hline Age in years, mean (SD) & $50.9(14.9)$ & $49.5(9.8)$ & $51.4(16.7)$ & NS \\
\hline Female, $N(\%)$ & $12(36.4)$ & $9(64.3)$ & $11(64.7)$ & NS \\
\hline $\begin{array}{l}\text { Disease duration in years, mean } \\
\text { (SD) }\end{array}$ & $10.8(8.5)$ & $14.4(15.3)$ & $17.4(13.7)$ & NS \\
\hline $\begin{array}{l}\text { Number of concomitant diseases, } \\
\text { mean (SD) }\end{array}$ & $1.5(1.6)$ & $1.6(1.8)$ & $2.9(3.1)$ & NS \\
\hline Number of medications, mean (SD) & $4.5(2.6)$ & $4.9(2.9)$ & $7.4(5.0)^{*}$ & $<0.05$ \\
\hline \multicolumn{5}{|l|}{ Assessments mean (SD) } \\
\hline \multicolumn{5}{|l|}{ Disease activities } \\
\hline Tender joint count & $5.2(5.5)$ & $9.9(4.8)^{*}$ & $13.2(7.7)^{*}$ & $<0.001$ \\
\hline Swollen joint count & $2.6(3.7)$ & $6.9(5.8)^{*}$ & $7.4(6.8)^{*}$ & 0.003 \\
\hline $\begin{array}{l}\text { Patient global assessment score } \\
(0-10 \mathrm{~cm})\end{array}$ & $0.92(0.76)$ & $1.95(0.90)^{*}$ & $2.29(1.38)^{*}$ & $<0.001$ \\
\hline Pain severity $(0-10 \mathrm{~cm})$ & $2.7(2.2)$ & $4.5(2.0)^{*}$ & $5.9(2.0)^{*}$ & $<0.001$ \\
\hline Dactylitis score & $1.4(1.4)$ & $3.8(3.2)$ & $3.8(2.0)^{*}$ & $<0.001$ \\
\hline Enthesitis score & $1.5(1.5)$ & $2.2(1.8)$ & $2.9(1.7)^{*}$ & 0.015 \\
\hline HAQ score & $0.4(0.5)$ & $1.1(0.8)^{*}$ & $1.5(0.8)^{*}$ & $<0.001$ \\
\hline \multicolumn{5}{|l|}{ Other symptoms } \\
\hline Pain interference & $2.6(2.6)$ & $5.0(2.6)$ & $6.0(2.0)$ & $<0.001$ \\
\hline Fatigue Impact Scale & $29.3(21.6)$ & $47.6(13.3)^{*}$ & $55.7(17.6)^{*}$ & $<0.001$ \\
\hline Fatigue Severity Scale & $3.3(1.8)$ & $5.5(1.0)^{*}$ & $5.4(1.7)^{*}$ & $<0.001$ \\
\hline Anxiety & $7.1(4.1)$ & $9.6(4.7)$ & $10.9(5.2)^{*}$ & 0.037 \\
\hline Depression & $4.5(4.4)$ & $7.0(3.4)$ & $9.3(4.0)^{*}$ & 0.001 \\
\hline $\begin{array}{l}\text { ACR2010FM: Widespread Pain } \\
\text { Index }\end{array}$ & $2.9(3.2)$ & $3.4(2.6)$ & $7.2(4.5) *$ & $<0.001$ \\
\hline $\begin{array}{l}\text { ACRFM2010: Symptom Severity } \\
\text { Scale (SSS) }\end{array}$ & $3.8(2.8)$ & $6.4(2.3)^{*}$ & $8.1(2.7)^{*}$ & $<0.001$ \\
\hline $\begin{array}{l}\text { CRFM2010: Polysymptomatic } \\
\text { Distress Scale (PDS) }\end{array}$ & $6.8(5.2)$ & $9.8(4.5)$ & $15.4(6.3)^{*}$ & $<0.001$ \\
\hline \multicolumn{5}{|l|}{ Quantitative sensory testing } \\
\hline von Frey filaments, mean (SD) & $4.61(0.5)$ & $4.63(0.4)$ & $4.71(0.4)$ & NS \\
\hline Algometer, mean (SD) & $641(236)$ & $626(380)$ & $558(334)$ & NS \\
\hline
\end{tabular}

$* p<0.05$ when compared with unlikely neuropathic pain group based on Dunnett's $t$ test post ANOVA. NS, not significant interference and impact, more severe fatigue and higher levels of anxiety and depression than UNP patients (Table 1).

Using the American College of Rheumatology 2010 fibromyalgia (ACR2010FM) questionnaire to assess "fibromyalgianess" (which can be assessed as a continuum as per the Polysymptomatic Distress Scale score [19]), according to the Widespread Pain Index (WPI), pain was significantly more widespread in the NP group. However, it did not significantly differ between the PNP and UNP groups. Both NP and PNP patients had statistically significantly higher Symptom Severity Scale (SSS), scores than UNP patients. The Polysymptomatic Distress Scale (PDS) scores indicated a significantly greater degree of "fibromyalgianess" in the NP group compared with the UNP group, with no significant difference between the PNP and UNP groups. Twenty patients ( 5 in UNP, 3 in PNP and 12 in NP) fulfilled ACR2010 criteria for the diagnosis of FM.

Overall PainDetect score correlated positively with measures of disease activity and associated symptoms as well as ACR2010FM PDS score and its components, WPI and SSS (Table 3).

Mechanical nociception as assessed by von Frey filaments were similar across 3 groups. PPT evaluated by electronic algometer was lowest in NP patients than that in UNP or PNP patients, but not significantly (Table 1). As PainDetect scores increased, PPT scores decreased (Table 3), indicating 
Table 3 Pearson correlation between PainDetect score with disease activity and associated symptoms

\begin{tabular}{lcc}
\hline Assessment parameter & Pearson correlation & $p$ value \\
\hline Widespread Pain Index & 0.416 & 0.001 \\
Symptom Severity Scale (SSS) & 0.643 & 0.000 \\
Polysymptomatic Distress Scale & 0.592 & 0.000 \\
HAQ score & 0.624 & 0.000 \\
Patient assessment score & 0.526 & 0.000 \\
Tender joint count & 0.556 & 0.000 \\
Swollen joint count & 0.351 & 0.005 \\
Pain severity & 0.631 & 0.000 \\
Pain interference & 0.620 & 0.000 \\
Fatigue Impact Scale & 0.583 & 0.000 \\
Fatigue Severity Scale & 0.609 & 0.000 \\
Fibromyalgia & 0.509 & 0.000 \\
Anxiety & 0.385 & 0.002 \\
Depression & 0.510 & 0.002 \\
Dactylitis score & 0.508 & 0.000 \\
Enthesitis score & 0.475 & 0.000 \\
Pressure pain threshold & -0.320 & 0.010 \\
\hline
\end{tabular}

an element of central sensitization, a mechanism in the development of neuropathic pain [30].

\section{Discussion}

The results of this study suggest there is a high prevalence of neuropathic-like pain (27\%) and possible neuropathic pain $(22 \%)$ in PsA patients. These patients experience greater levels of pain, and all measures of disease activity were higher. This is similar to a Danish study by Rifbjerg-Madsen et al. [31] investigating the prevalence of neuropathic pain in patients with RA, PsA and other spondyloarthritidies using the PainDetect score, which found a prevalence of neuropathic pain in PsA of $28 \%$, which was significantly higher than the two other types of arthritis investigated. Patients with NP have higher fatigue, anxiety and depression scores. Similar to our results, a large transatlantic study by Taylor et al. [3] in RA patients found that patients with NP having significantly higher pain severity and measures of disease activity. Their study also showed that pain levels were related to fatigue levels and severe pain to be associated with depression.

A limitation of this study may be that our sample population included patients with FM-while only one patient stated they had FM in the demographics questionnaire, according to the ACR $2010 \mathrm{FM}$ criteria [32] there were 20 patients with fibromyalgia (NN 5, PN 3, LNP 12), suggesting that concomitant fibromyalgia is under-diagnosed in patients with PsA. The PainDetect tool has been shown to not be as useful at identifying neuropathic pain in patients with FM [33].
Significantly higher prevalence of FM has been found in PsA patients compared with non-PsA individuals [34], and FM has been found to be associated with worse PsA disease activity [35]. It is also interesting to note that patients with primary FM and psoriasis may be mistaken for patients with PsA due to the similarity in presentation [36]. Patients with neuropathic pain and patients with FM can describe similar sensory perceptions - including burning and prickling pain and allodynia [37]. Not excluding PsA patients with fibromyalgia, or not creating a separate group for such patients, does not permit evaluation of the effect of fibromyalgia on neuropathic pain, for example, whether PsA and fibromyalgia in the same patient may have an additive effect and lead to worse neuropathic pain. Previous studies investigating the prevalence of neuropathic pain, as identified by the PainDetect score, in patients with fibromyalgia and chronic widespread pain found that the majority of these patients have neuropathic pain $[38,39]$.

Another limitation of this study was the inclusion of patients with type 2 diabetes. Diabetic neuropathy is a common complication of diabetes, which has a varying prevalence depending on the definition of diabetic neuropathy, but affects a greater proportion of diabetics as the time post diagnosis increases [40]. In industrialised countries, diabetic neuropathy is the most common type of neuropathy and neuropathic pain is a common occurrence in length-dependent diabetic neuropathy (diabetic neuropathy with an initial predilection for longer neurons before shorter neurons, affecting $80 \%$ of diabetic neuropathy) [41]. Painful diabetic neuropathy has been shown to affect $1 / 3$ of community-based diabetics in a large English population, with having type 2 diabetes being one of the factors of patients with diabetes in whom painful diabetic neuropathy was more prevalent [42]. Diabetic peripheral neuropathy is one of a number of causes of neuropathic pain, which can be detected as probable neuropathic pain using the PainDetect score (44) (other causes of neuropathic pain include chronic lower back pain, post-surgical neuropathy, post trauma neuropathy, HIV, trigeminal neuralgia, post-herpetic neuralgia $[13,43])$. A previous study found an increased prevalence of diabetes in patients with PsA compared with nonPsA patients and suggested that PsA may have an association with diabetes in females, in particular [44]. Similarly to FM, by not excluding or creating a separate group for the PsA patients with diabetes, it is not possible to assess whether having diabetes has an effect on the neuropathic pain experienced by PsA patients. The demographic data of this study found diabetes was the second most prevalent co-morbidity in the study population.

A study investigating the similarities and differences of diabetic painful neuropathy and FM found that both groups of patients describe their pain as burning/prickling pain with light touch allodynia [37], which has similarities to the characteristics of neuropathic pain described in inflammatory 
arthritides [11]. While this means that some of the results of the investigations in this study may be secondary to diabetes, in particular type 2 diabetes, and FM, rather than purely PsA, not excluding patients with these conditions makes the study population more similar to the UK population of patients with PsA. This gives our results higher external validity, and an indication that individuals in this population have a prevalence of conditions that may contribute to neuropathic pain.

A key strength of this study was assessing these patients with the ACR2010FM questionnaire. The majority of NP patients $(12 / 17,71 \%)$ fulfilled the criteria for FM. One may interpret our data as evidence of concurrent unrecognised FM in patients with PsA - the prevalence of FM in patients with PsA $(20 / 64,31 \%)$ is much higher than that in the general population of 5\% [45]. Furthermore, patients with PNP seem to represent an intermediate "fibromyalgic" phenotype. Only 3 out of 14 patients (21\%) fulfilled ACR2010 criteria for FM. Yet their pain severity, disease activity and associated symptoms, WPI and SSS were higher than those of UNP patients. The correlation between PainDetect score with pain severity, measures of disease activity, fatigue, depression, anxiety, WPI, SSS, and PPT strongly suggests a continuum rather than 2 distinct populations of patients. Our interpretation is that "fibromyalgianess" in PsA is a continuum and represents abnormal pain processing in patients experiencing chronic nociceptive pain.

The weaknesses of this study include lack of a control group to compare the study groups with, but as a preliminary study, this is acceptable as the researchers were looking to see if a pattern exists which could be tested more robustly in future. The sample size of this study is relatively small so negative results may be due to a lack of statistical power. Lack of follow-up data meant that the stability of neuropathic pain phenotypes cannot be evaluated. It is also unclear whether more active disease predisposes to NP/fibromyalgia or measures of disease activity are erroneously higher in patients with $\mathrm{NP} /$ fibromyalgia.

\section{Conclusion}

There is a high prevalence of neuropathic-like pain in psoriatic arthritis. The causes of this are unknown, and a better understanding of how this develops may help develop better treatments for PsA patients in the future.

PsA patients are severely affected by a variety of symptoms beyond pain and disease activity, which have detrimental biopsychosocial effects. This indicates that their care must be tailored to address all of these problems experienced to achieve the most effective management and therefore best possible quality of life.

Acknowledgements The CREATE Centre was funded by Arthritis Research UK and Health and Care Research Wales.

\section{Compliance with ethical standards}

Disclosures None.

Open Access This article is distributed under the terms of the Creative Commons Attribution 4.0 International License (http:// creativecommons.org/licenses/by/4.0/), which permits unrestricted use, distribution, and reproduction in any medium, provided you give appropriate credit to the original author(s) and the source, provide a link to the Creative Commons license, and indicate if changes were made.

\section{References}

1. Heiberg T, Kvien TK (2002) Preferences for improved health examined in 1,024 patients with rheumatoid arthritis: pain has highest priority. Arthritis Rheum 47(4):391-397

2. Atzeni F, Masala IF, Salaffi F, Di Franco M, Casale R, Sarzi-Puttini P (2015) Pain in systemic inflammatory rheumatic diseases. Best Pract Res Clin Rheumatol 29(1):42-52

3. Taylor P, Manger B, Alvaro-Gracia J, Johnstone R, Gomez-Reino J, Eberhardt E, Wolfe F, Schwartzman S, Furfaro N, Kavanaugh A (2010) Patient perceptions concerning pain management in the treatment of rheumatoid arthritis. J Int Med Res 38(4):1213-1224

4. McDougall JJ (2006) Arthritis and pain. Neurogenic origin of joint pain. Arthritis Res Ther 8(6):220

5. Woolf CJ, Mannion RJ (1999) Neuropathic pain: aetiology, symptoms, mechanisms, and management. Lancet 353(9168):19591964

6. Treede RD, Jensen TS, Campbell JN, Cruccu G, Dostrovsky JO, Griffin JW et al (2008) Neuropathic pain: redefinition and a grading system for clinical and research purposes. Neurology 70(18):1630 1635

7. Baron R (2006) Mechanisms of disease: neuropathic pain —a clinical perspective. Nat Rev Neurol 2(2):95

8. Garland EL (2012) Pain processing in the human nervous system: a selective review of nociceptive and biobehavioral pathways. Prim Care 39(3):561-571

9. Siao P, Cros DP (2003) Quantitative sensory testing. Phys Med Rehabil Clin N Am 14(2):261-286

10. Melzack R, Coderre TJ, Katz J, Vaccarino AL (2001) Central neuroplasticity and pathological pain. Ann N Y Acad Sci 933: $157-174$

11. Koop SM, ten Klooster PM, Vonkeman HE, Steunebrink LM, van de Laar MA (2015) Neuropathic-like pain features and crosssectional associations in rheumatoid arthritis. Arthritis Res Ther 17:237

12. Pollard LC, Ibrahim F, Choy EH, Scott DL (2012) Pain thresholds in rheumatoid arthritis: the effect of tender point counts and disease duration. J Rheumatol 39(1):28-31

13. Colloca L, Ludman T, Bouhassira D, Baron R, Dickenson AH, Yarnitsky D, Freeman R, Truini A, Attal N, Finnerup NB, Eccleston C (2017) Neuropathic pain. Nat Rev Dis Primers 3:17002

14. O'Connor AB (2009) Neuropathic pain. Pharmacoeconomics. 27(2):95-112

15. Haanpää ML, Backonja MM, Bennett MI, Bouhassira D, Cruccu G, Hansson PT, Jensen TS, Kauppila T, Rice AS, Smith BH, Treede RD (2009) Assessment of neuropathic pain in primary care. Am J Med 122(10):S13-S21

16. Greenspan JD (2001) Quantitative assessment of neuropathic pain. Curr Pain Headache Rep 5(2):107-113 
17. Freynhagen R, Baron R, Gockel U, Tölle TR (2006) painDETECT: a new screening questionnaire to identify neuropathic components in patients with back pain. Curr Med Res Opin 22(10):1911-1920

18. Wolfe F, Clauw DJ, Fitzcharles MA, Goldenberg DL, Katz RS, Mease P, Russell AS, Russell IJ, Winfield JB, Yunus MB (2010) The American College of Rheumatology preliminary diagnostic criteria for fibromyalgia and measurement of symptom severity. Arthritis Care Res 62(5):600-610

19. Wolfe F, Brähler E, Hinz A, Häuser W (2013) Fibromyalgia prevalence, somatic symptom reporting, and the dimensionality of polysymptomatic distress: results from a survey of the general population. Arthritis Care Res 65(5):777-785

20. Tan G, Jensen MP, Thornby JI, Shanti BF (2004) Validation of the Brief Pain Inventory for chronic nonmalignant pain. J Pain 5(2): 133-137

21. Fisk JD, Ritvo PG, Ross L, Haase DA, Marrie TJ, Schlech WF (1994) Measuring the functional impact of fatigue: initial validation of the fatigue impact scale. Clin Infect Dis 18(Supplement 1):S79 S83

22. Jason LA, Evans M, Brown M, Porter N, Brown A, Hunnell J, Anderson V, Lerch A (2011) Fatigue scales and chronic fatigue syndrome: issues of sensitivity and specificity. Disabil Stud Q 31(1):pii1375

23. Bjelland I, Dahl AA, Haug TT, Neckelmann D (2002) The validity of the Hospital Anxiety and Depression Scale: an updated literature review. J Psychosom Res 52(2):69-77

24. Bruce B, Fries JF (2005) The health assessment questionnaire (HAQ). Clin Exp Rheumatol 23(5):S14

25. Freynhagen R, Baron R, Gockel U, Tölle TR (2006) Pain DETECT: a new screening questionnaire to identify neuropathic components in patients with back pain. Curr Med Res Opin 22(10): 1911-1920

26. Choy EH, Khoshaba B, Cooper D, MacGregor A, Scott DL (2008) Development and validation of a patient-based disease activity score in rheumatoid arthritis that can be used in clinical trials and routine practice. Arthritis Rheum 59(2):192-199

27. Somedic SenseLab. Algometer. [Date unknown] Available at: http://somedic.com/en/algometer.html Accessed 12/05/19

28. North Coast Medical Inc. Touch Test @ Sensory Evaluators. 2019; Available at: https://www.ncmedical.com/item_1278.html Accessed 12/05/19

29. Abiebr. Hospital Anxiety and Depression Scale. 2017; Available at: http://www.abiebr.com/node/410. Accessed 07/12, 2017

30. Campbell JN, Meyer RA (2006) Mechanisms of neuropathic pain. Neuron. 52(1):77-92

31. Rifbjerg-Madsen S, Christensen AW, Christensen R, Hetland ML, Bliddal H, Kristensen LE, Danneskiold-Samsøe B, Amris K (2017) Pain and pain mechanisms in patients with inflammatory arthritis: a Danish nationwide cross-sectional DANBIO registry survey. PLoS One 12(7):e0180014

32. Wolfe F, Clauw DJ, Fitzcharles MA, Goldenberg DL, Häuser W, Katz RS, Mease P, Russell AS, Russell IJ, Winfield JB (2011) Fibromyalgia criteria and severity scales for clinical and epidemiological studies: a modification of the ACR Preliminary Diagnostic Criteria for Fibromyalgia. J Rheumatol 38(6):1113-1122
33. Gauffin J, Hankama T, Kautiainen H, Hannonen P, Haanpää M (2013) Neuropathic pain and use of Pain DETECT in patients with fibromyalgia: a cohort study. BMC Neurol 13(1):21

34. Magrey MN, Antonelli M, James N, Khan MA (2013) High frequency of fibromyalgia in patients with psoriatic arthritis: a pilot study. Arthritis. 2013:1-4

35. Brikman S, Furer V, Wollman J, Borok S, Matz H, Polachek A, Elalouf O, Sharabi A, Kaufman I, Paran D, Elkayam O (2016) The effect of the presence of fibromyalgia on common clinical disease activity indices in patients with psoriatic arthritis: a cross-sectional study. J Rheumatol 43(9):1749-1754

36. Marchesoni A, Atzeni F, Spadaro A, Lubrano E, Provenzano G, Cauli A, Olivieri I, Melchiorre D, Salvarani C, Scarpa R, SarziPuttini P (2012) Identification of the clinical features distinguishing psoriatic arthritis and fibromyalgia. J Rheumatol 39(4):849-855

37. Koroschetz J, Rehm SE, Gockel U, Brosz M, Freynhagen R, Tölle TR, Baron R (2011) Fibromyalgia and neuropathic pain-differences and similarities. A comparison of 3057 patients with diabetic painful neuropathy and fibromyalgia. BMC Neurol 11(1):55

38. Rehm SE, Koroschetz J, Gockel U, Brosz M, Freynhagen R, Tölle TR, Baron R (2010) A cross-sectional survey of 3035 patients with fibromyalgia: subgroups of patients with typical comorbidities and sensory symptom profiles. Rheumatology. 49(6):1146-1152

39. Amris K, Jespersen A, Bliddal H (2010) Self-reported somatosensory symptoms of neuropathic pain in fibromyalgia and chronic widespread pain correlate with tender point count and pressurepain thresholds. PAIN ${ }^{\circledR} 151(3): 664-669$

40. Greene DA, Stevens MJ, Feldman EL (1999) Diabetic neuropathy: scope of the syndrome. Am J Med 107(2):2-8

41. Said G (2007) Diabetic neuropathy - a review. Nat Rev Neurol 3(6):331

42. Abbott CA, Malik RA, van Ross ER, Kulkarni J, Boulton AJ (2011) Prevalence and characteristics of painful diabetic neuropathy in a large community-based diabetic population in the UK. Diabetes Care 34(10):2220-2224

43. Kudel I, Hopps M, Cappelleri JC, Sadosky A, King-Concialdi K, Liebert R, Parsons B, Hlavacek P, Alexander AH, DiBonaventura MD, Markman JD (2019) Characteristics of patients with neuropathic pain syndromes screened by the painDETECT questionnaire and diagnosed by physician exam. J Pain Res 12:255-268

44. Dreiher J, Freud T, Cohen AD (2013) Psoriatic arthritis and diabetes: a population-based cross-sectional study. Dermatol Res Pract 2013:1-7

45. Jones GT, Atzeni F, Beasley M, Flüß E, Sarzi-Puttini P, Macfarlane GJ (2015) The prevalence of fibromyalgia in the general population: a comparison of the American College of Rheumatology 1990, 2010, and modified 2010 classification criteria. Arthritis Rheum 67(2):568-575. https://doi.org/10.1002/art.38905

Publisher's note Springer Nature remains neutral with regard to jurisdictional claims in published maps and institutional affiliations. 